Canadian

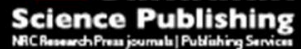

Canadian Journal of Physiology and Pharmacology Revue canadienne de physiologie et pharmacologie

\title{
Myocardial homing of mesenchymal stem cells following intrapericardial application and amplification by inflammation - An experimental pilot study
}

\begin{tabular}{|r|l|}
\hline Journal: & Canadian Journal of Physiology and Pharmacology \\
\hline Manuscript ID & cjpp-2016-0373.R1 \\
\hline Manuscript Type: & Brief Report \\
\hline Date Submitted by the Author: & 15 -Sep-2016 \\
\hline Complete List of Authors: & $\begin{array}{l}\text { Jung, Nina; University Medical Center Giessen and Marburg, Department of } \\
\text { Medicine, Pulmonary and Critical Care Medicine } \\
\text { Rupp, Heinz; Philipps University, } \\
\text { Koczulla, Rembert; University Medical Center Giessen and Marburg, } \\
\text { Department of Medicine, Pulmonary and Critical Care Medicine } \\
\text { Vogelmeier, Claus; University Medical Center Giessen and Marburg, } \\
\text { Department of Medicine, Pulmonary and Critical Care Medicine } \\
\text { Alter, Peter; University of Marburg, Medicine, Pulmonary and Critical Care } \\
\text { Medicine }\end{array}$ \\
\hline Keyword: & Stem cells, Pericarditis, Myocardial homing, Inflammation, Heart failure \\
\hline \multicolumn{2}{|c}{} \\
\hline
\end{tabular}




\title{
Myocardial homing of mesenchymal stem cells following intrapericardial application and amplification by inflammation - An experimental pilot study
}

\author{
Jung, Nina ${ }^{1}$, Rupp, Heinz $\dagger$, Koczulla, A. Rembert ${ }^{1}$, Vogelmeier, Claus F. ${ }^{1}$, Alter, Peter ${ }^{1}$ \\ ${ }^{1}$ Department of Medicine, Pulmonary and Critical Care Medicine, Philipps University, Marburg, \\ Germany
}

Word count

1356

\section{Address for correspondence}

Nina Jung, MD \& Peter Alter, Prof, MD, FESC

Department of Medicine, Pulmonary and Critical Care Medicine

University Medical Center Giessen and Marburg

Philipps-University Marburg, Germany

Baldingerstrasse

35033 Marburg, Germany

Phone: +4964215866140

Fax: $\quad+4964215866149$

Email: alter@uni-marburg.de, jungnin@staff.uni-marburg.de,nina-jung@gmx.de 


\section{Abstract}

Recent studies demonstrated potential effects of stem cells on cardiac function in heart failure. However, influences of the technique of application remained undetermined. In the present study, the pericardial sac was used as depot for fluorescent-labeled mesenchymal stem cells in rats. To evaluate influences of inflammation on cell homing, a sterile pericarditis was induced by talc. It is shown that intrapericardial stem cells application is sufficient to provide myocardial penetration. The extent of homing was amplified by inflammation in a talc-induced pericarditis.

\section{Key words}

Stem cells, Pericarditis, Myocardial homing, Inflammation, Heart failure, Pericardium 


\section{Introduction}

Although findings of previous studies on stem cell therapy in chronic heart failure were ambiguous, beneficial effects on cardiac function have been described for distinct types of therapy (Sanganalmath and Bolli 2013). Intracoronary, intramyocardial and retrograde stem cell transplantation has been applied; however, the optimal approach remained still unknown, and use of the pericardial sac has not been sufficiently explored in this regard. The pericardium is known as appropriate target of antiinflammatory drug delivery, e.g. for treatment of pericarditis (Adler et al. 2015; Alter et al. 2013; Glück et al. 2016; Maisch and Pankuweit 2012). In addition, it is known that drugs applied into the pericardial space can penetrate the myocardium (Marcano et al. 2013). There are yet only very few studies on myocardial homing of stem cells after intrapericardial administration (Blázquez et al. 2015; Blázquez et al. 2016; Branco et al. 2009). None of them considered amplifying effects of local inflammation.

Mesenchymal stem cells exhibit a self-renewal capacity and bear the potential of multiple ways of further differentiation (Pittenger et al. 2000). Multipotent cells can be isolated from bone marrow (Zhang and Chan 2010).

\section{Material and methods}

The present study examines influences of inflammation on myocardial stem cell homing after injection of allogene mesenchymal stem cell (MSC) into the pericardial space of 10 Wistar WU rats. In 5 of these experimental animals, a sterile pericarditis was induced by talc. In addition, in 5 animals the surgical intervention was used as sham procedure without stem cell application (Figure 1). All experimental protocols were approved by the local ethics committee. 
For stem cell extraction, male rats were euthanized and bone marrow aspirate was isolated. Cell suspension was washed and expanded using DMEM (Dulbecco's Modified Eagle's Medium) containing $10 \%$ fetal bovine serum (FBS), penicillin and streptomycin. Non-adherent hematopoietic cells were removed. To show the multipotent nature of these MSC, standard protocols were used to induce adipogenic (Choi et al. 2008) and osteogenic (Salasznyk et al. 2004) differentiation, which was confirmed by Oil Red $\mathrm{O}$ and Alizarin Red staining, respectively.

Stem cell application was performed via open chest surgery during deep anesthesia. Age and weight matched female Wistar WU rats served as acceptors. These Rats were anesthetized with isoflurane and ventilated by endotracheal intubation. The pericardial space was accessed by right-sided thoracotomy. Full doses of $1{ }^{*} 10^{6} \mathrm{PKH}-26$ labeled MSC were injected into pericardial space in 10 acceptor rats. In a subgroup of 5 animals, sterile pericarditis was induced by $30 \mu \mathrm{g} / \mathrm{kg}$ talc. A balanced electrolyte solution was used for controls $(n=5)$. Two days after mesenchymal stem cell administration acceptor rats were euthanized, histological examination was performed using frozen slices and the number of detected cells was extrapolated to the complete cardiac mass as measured (Rupp et al. 2010).

Statistical comparisons were made by Kruskal-Wallis analysis of variance (ANOVA); post hoc analysis was made by Student-Newmann Keuls Method (Med Calc, MedCalc Software, Ostend, Belgium). Statistical significance was assumed at $p$ $<0.05$

\section{Results}

No experimental or periprocedural deaths occurred and no significant differences between pre- and postprocedural body weight were observed among the groups 
(Table 1). In animals with sterile pericarditis, a thickened pericardial layer was identified. The pericardial mass normalized to total body weight (BW) was significantly increased in pericarditis when compared with non-pericarditis or controls $(p<0.05)$, while stem cell application without pericarditis resulted not in an increase of pericardial mass (Table 1). Previous data showed that talc alone lead to a similar increase of pericardial mass (König 2002). No significant differences of myocardial weight normalized to total body mass were observed among the groups.

Myocardial homing of stem cells was shown by microscopic evaluation of PKH26 labeled cells (Figure 2). No specific fluorescence was observed in controls. Histological analysis showed no evidence of a specific homing pattern. Myocardial homing was indicated by a significant increase of stem cells when compared with controls $(p<0.05)$. Of note, the extent of homing was significantly increased in pericarditis when compared with non-pericarditis and controls $(p<0.05$, Figure 2$)$.

\section{Discussion}

In the present study, it was shown that stem cells applied into the pericardial space penetrate the epicardial border into the myocardium. To our best knowledge, this is the first study reporting effects of inflammation in terms of a sterile pericarditis on increased myocardial homing. MSC viability, the proliferative behavior and phenotypic pattern appears unaffected by exposure to pericardial fluid as previously shown (Blázquez et al. 2015). Pericardial fluid with a low turnover rate has the potential to serve as therapeutic depot, which allows delivery of high doses of MSC into pericardial sac. 
It is a limitation of the present study that invasion of sex mismatched cells was not confirmed by a second method, e.g. real-time quantitative PCR (qPCR) or fluorescence in situ hybridization (FISH). However, the feasibility of the concept is in line with other recent studies, in which myocardial homing of intrapericardially applied stem cells was shown (Blázquez et al. 2015; Blázquez et al. 2016; Branco et al. 2009). Further studies are required to investigate the detailed pathway of stem cell homing; there is evidence that inflammation could be play an essential role (Zhang et al. 2016). Potential prognostic benefits of this method of stem cell application need to be addressed in future studies.

\section{Conclusions}

In contrast to previous methods of application, a pericardial approach bears several potential advantages: First, pericardial fluid has contact to large epi-/myocardial areas, which could be helpful for treatment of diffuse myocardial diseases, e.g. cardiomyopathies. Thus, the targeted area of myocardium is beyond the proportion as addressed by local intracoronary application. Second, the pericardial sac serves as depot and thus provides longer penetration times when compared with an intracoronary injection. Noteworthy, inflammation appears to increase the extent of stem cell penetration to the myocardium. Third, microvascular obstruction, as frequently observed in acute coronary syndrome, impedes the vascular flow and thus an intracoronary stem cell delivery into the area of ischemia. In turn, stem cell application itself is expected to lead to microvascular obstruction. 
In sum, the pericardial approach appears a favorable technique that should be envisaged for stem cell application in heart failure. The clinical feasibility and potential benefits remain to be shown in further studies.

\section{References}

Adler, Y., Charron, P., Imazio, M., Badano, L., Barón-Esquivias, G., Bogaert, J., et al. 2015. 2015 ESC Guidelines for the diagnosis and management of pericardial diseases: The Task Force for the Diagnosis and Management of Pericardial Diseases of the European Society of Cardiology (ESC)Endorsed by: The European Association for Cardio-Thoracic Surgery (EACTS). Eur. Heart J. 36(42): 2921-2964.

Alter, P., Figiel, J. H., Rupp, T. P., Bachmann, G. F., Maisch, B., and Rominger, M. B. 2013. MR, CT, and PET imaging in pericardial disease. Heart Fail. Rev. 18(3): 289-306.

Blázquez, R., Sánchez-Margallo, F. M., Crisóstomo, V., Báez, C., Maestre, J., García-Lindo, M., et al. 2015. Intrapericardial administration of mesenchymal stem cells in a large animal model: a bio-distribution analysis. PLoS One, 10(3): e0122377.

Blázquez, R., Sánchez-Margallo, F. M., Crisóstomo, V., Báez, C., Maestre, J., Álvarez, V., et al. 2016. Intrapericardial Delivery of Cardiosphere-Derived Cells: An Immunological Study in a Clinically Relevant Large Animal Model. PLoS One, 11(2): e0149001.

Branco, E., Fioretto, E. T., Cabral, R., Palmera, C. A., Gregores, G. B., Stopiglia, A. J., et al. 2009. Myocardial homing after intrapericardial infusion of bone marrow cells. Arq. Bras.

Cardiol.(Brazil), 93: e50-53.

Choi, K. M., Seo, Y. K., Yoon, H. H., Song, K. Y., Kwon, S. Y., Lee, H. S., et al. 2008. Effect of ascorbic acid on bone marrow-derived mesenchymal stem cell proliferation and differentiation. Journal of Bioscience and Bioengineering, 105(6): 586-594.

Glück, T., Rupp, H., and Alter, P. 2016. Mechanisms increasing n-3 highly unsaturated fatty acids in the heart. Can. J. Physiol. Pharmacol. 94(3): 309-323.

König, H. 2002. PPARalpha induzierte Hemmung der TNFalpha-mRNA-Expression bei durch Talkum induzierter Perikarditis der Ratte. PhD Dissertation, Philipps-Universität-Marburg, Germany.

Maisch, B., and Pankuweit, S. 2012. Current treatment options in (peri)myocarditis and inflammatory cardiomyopathy. Herz, 37(6), 644-656.

Marcano, J., Campos, K., Rodriguez, V., Handy, K., Brewer, M. A., and Cohn, W. E. 2013. Intrapericardial delivery of amiodarone rapidly achieves therapeutic levels in the atrium. Heart Surg. Forum, 16(5): E279-286.

Pittenger, M. F., Mosca, J. D., and McIntosh, K. R. 2000. Human mesenchymal stem cells: progenitor cells for cartilage, bone, fat and stroma. Curr. Top. Microbiol. Immunol. 251: 3-11.

Rupp, H., Rupp, T. P., Alter, P., Jung, N., Pankuweit, S., and Maisch, B. 2010. Intrapericardial procedures for cardiac regeneration by stem cells Need for minimal invasive access (AttachLifter) to the normal pericardial cavity. Herz, 35(7): 458-465. 
Salasznyk, R. M., Williams, W. A., Boskey, A., Batorsky, A., and Plopper, G. E. 2004. Adhesion to Vitronectin and Collagen I Promotes Osteogenic Differentiation of Human Mesenchymal Stem Cells. J. Biomed. Biotechnol. 2004(1): 24-34.

Sanganalmath, S. K., and Bolli, R. 2013. Cell therapy for heart failure: a comprehensive overview of experimental and clinical studies, current challenges, and future directions. Circ. Res. 113(6): 810-834.

Zhang, L., and Chan, C. 2010. Isolation and enrichment of rat mesenchymal stem cells (MSCs) and separation of single-colony derived MSCs. J. Vis. Exp.(37): 1852.

Zhang, S. J., Song, X. Y., He, M., and Yu, S. B. 2016. Effect of TGF-beta1/SDF-1/CXCR4 signal on BM-MSCs homing in rat heart of ischemia/perfusion injury. Eur. Rev. Med. Pharmacol. Sci. 20(5): 899-905. 


\section{Figure legends}

Figure 1. Study protocol. Histological examination was performed in 39 slides of each group ( 7 slides were taken in the first animal of each group, 8 slides per animal for all further were examined).

Figure 2. Histological examination (left panel): HE staining (upper row) and fluorescence micrograph (lower row) of the same tissue region of myocardium 2 days after sham procedure (A and B), post MSC application without ( $C$ and $D)$ and with sterile pericarditis (E and F). No specific fluorescence was found in controls (B). PKH26 positive staining on mesenchymal stem cells in myocardium (arrows) and in pericardium (ellipse) are shown ( $D$ and $F$ ). The extrapolated total number of homed stem cells (right panel) were increased after MSC application when compared with controls. Of note, the extent of myocardial homing was significantly increased in pericarditis group when compared with non-pericarditis group. 
$10 / 10$

\section{Declaration of interests}

The authors report no relationships that could be construed as a conflict of interest.

\section{Acknowledgements}

The study was supported by the Marburg Cardiac Society. 


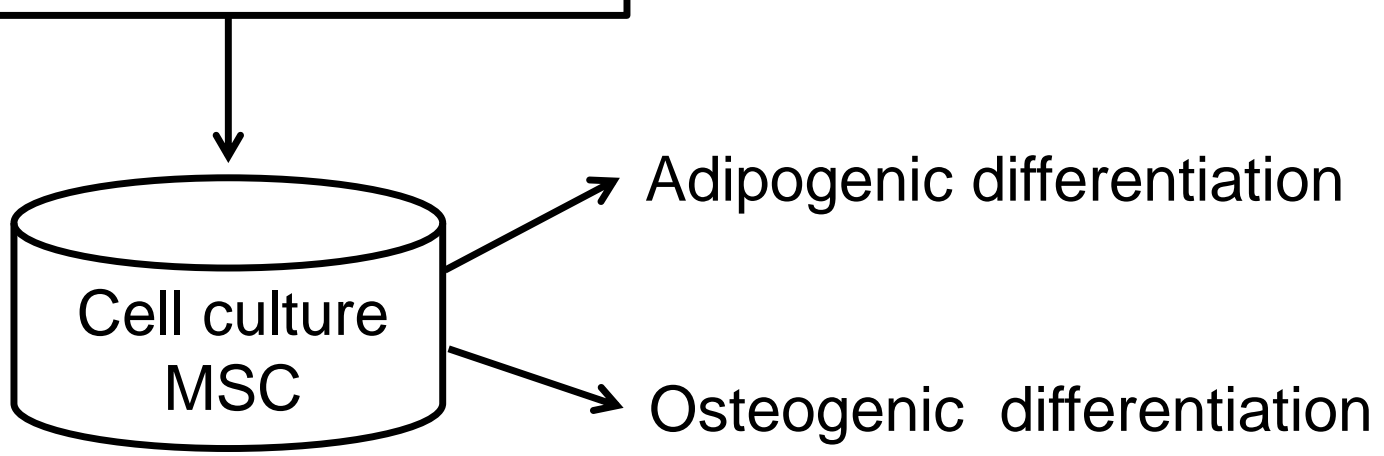

MSC application into the pericardial space of acceptor rats

\begin{tabular}{|c|c|c|}
\hline Controls & $\begin{array}{l}\text { Stem cells } \\
\qquad n=5\end{array}$ & $\begin{array}{c}\text { Stem cells } \\
+ \\
\text { Pericarditis } \\
n=5\end{array}$ \\
\hline $\begin{array}{c}\text { Balanced } \\
\text { electrolyte } \\
\text { solution }\end{array}$ & $\begin{array}{l}1^{*} 10^{6} \mathrm{PKH}-26 \\
\text { labeled MSC }\end{array}$ & $\begin{array}{c}1^{*} 10^{6} \mathrm{PKH}-26 \\
\text { labeled MSC } \\
+ \\
30 \mu \mathrm{g} / \mathrm{kg} \\
\text { talc }\end{array}$ \\
\hline
\end{tabular}

Histological examination after 2 days

39 Slices 


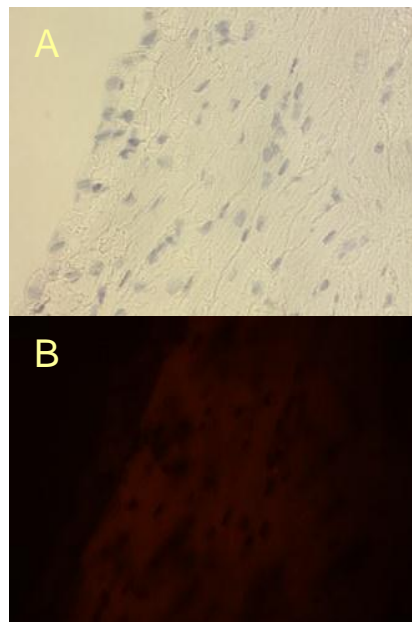

Controls

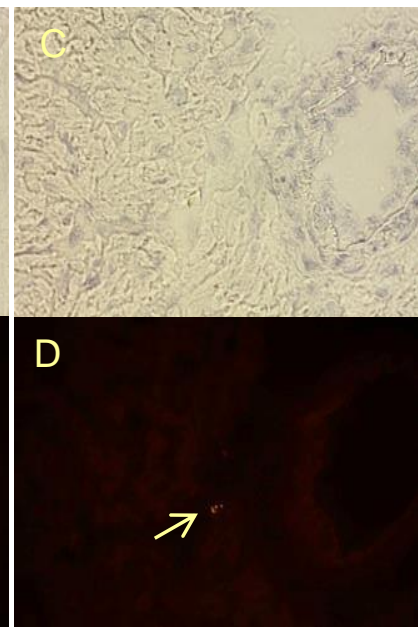

Stem cell application

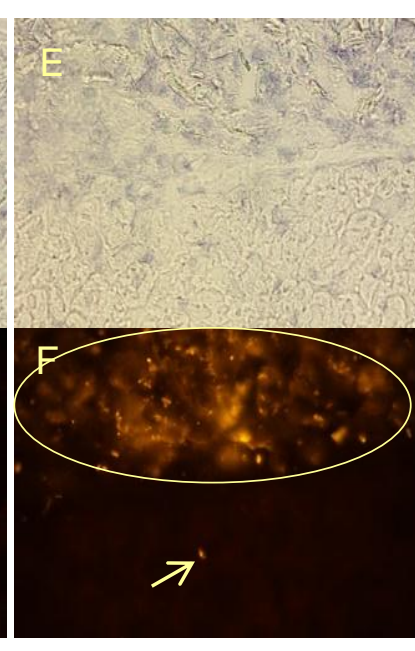

Stem cell application

Pericarditis

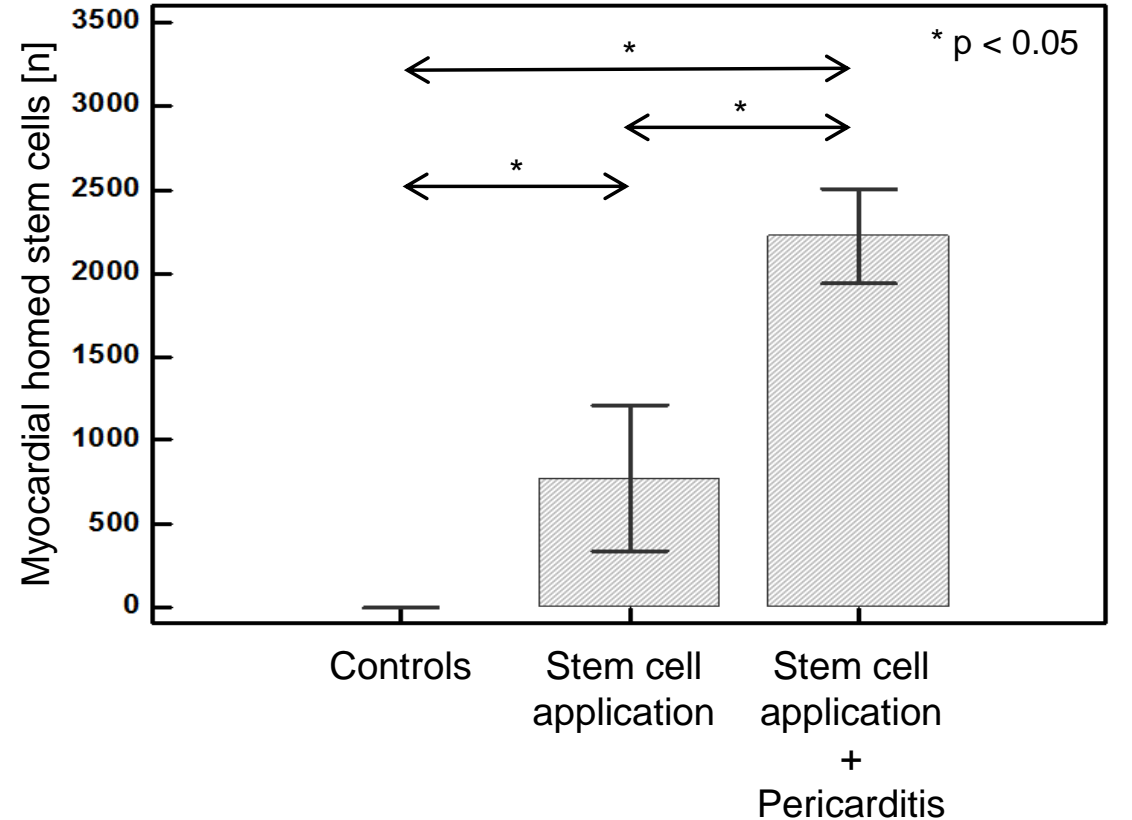

Pericarditis 
Table 1. Characteristics of acceptor rats

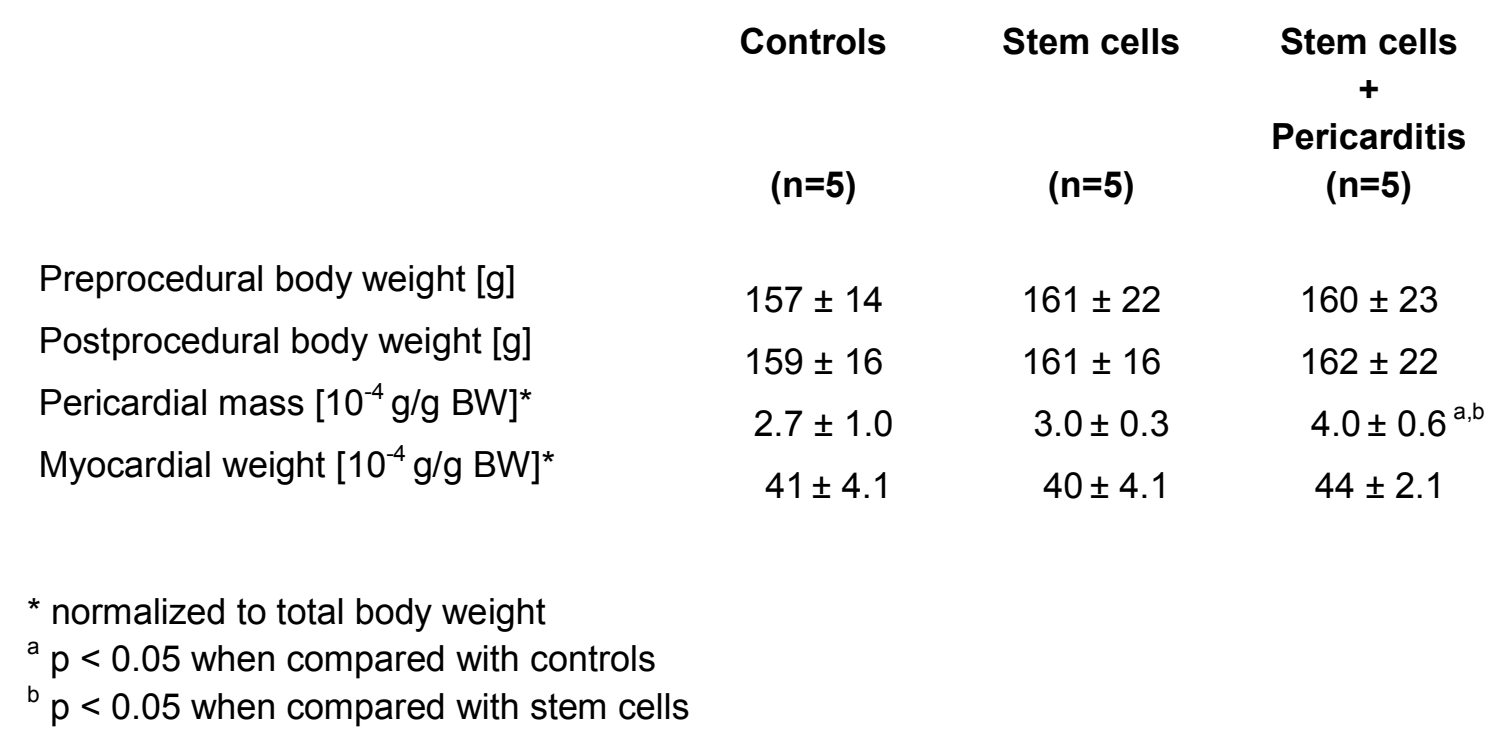

